\title{
Design Domain: Created Space, Creative Space
}

Thea Stevens is an academic coordinator and lecturer at the Glasgow School of Art, Scotland, UK. As well as coordinating Design Domain in the School of Design, she is a PhD Coordinator, and her broad research and teaching interests focus on ideological frameworks in visual, material and built culture, as well as pedagogies in art \& design higher education. Thea holds a Master's in History of Art from the University of Warwick, and a PhD from the University of Glasgow. Her profile and her ongoing and published research can be found at: http://radar.gsa.ac.uk/profile/664. Contact address: School of Design, Reid Building, Glasgow School of Art, 164 Renfrew Street, Glasgow G3 6RQ, UK. Email: t.stevens@gsa.ac.uk

\begin{abstract}
In this article, I describe and explore Design Domain, a large-cohort course for which I am academic coordinator and which is enacted across six design programmes at the Glasgow School of Art (GSA). I unpack Design Domain's context and intentionality as a 'created space', where student learners are exposed to different ways of thinking, making and doing, with an emphasis on working within discipline but pushing boundaries beyond the discipline. Next, I evaluate Design Domain as a 'creative space', unpacking its lineaments and evaluating its positives and challenges. Then, I set out initial reflections on the taxonomy of disciplinarities, arguing that these can be usefully reappraised when applied to a pedagogical framework like Design Domain, which blends predominantly individual learning with particular and specific points of collective commonality of purpose and action. Finally, I describe how I will go onto develop my understanding via an action research informed evaluation of a recent Design Domain project in Communication Design, where students of graphic design, photography and illustration worked together. I frame the type of critical questions I might ask of staff and student respondents in an action research informed evaluation study, and I offer a preliminary conclusion: that it is more appropriate to focus on ways of thinking than prescribing ways of doing, and that this might bring practice and process into a more adaptive theoreticalframework.
\end{abstract}

\section{Keywords}

Design Domain; art \& design higher education; created space; creative; space; disciplinarities 


\section{Introduction}

In this article, and from the standpoint of its academic coordinator, I discuss Design Domain, a course at the Glasgow School of Art (GSA) in terms of its context, intentionality and enactment. I interrogate Design Domain as a 'created space' where student learners are exposed to different ways of thinking, making and doing, with an emphasis on working within discipline but pushing boundaries beyond discipline, too. I also evaluate Design Domain as a 'creative space', unpacking its lineaments and evaluating its positives and challenges. I then set out initial reflections on the taxonomy of disciplinarities, arguing that these can be usefully reappraised when applied to Design Domain, which blends predominantly individual learning with particular and specific points of collective commonality of purpose and action. Finally, I describe how I will develop an action research informed evaluation of a recent Design Domain project in Communication Design, where students of graphic design, photography and illustration worked together. I frame the types of critical questions I might ask of staff and student respondents, and I offer a preliminary conclusion, or perhaps a suspicion to be more fully tested: that it is more appropriate to focus on ways of thinking than prescribing ways of doing, and that this might bring practice and process into a more adaptive theoreticalframework.

\section{Design Domain: context and intentionality}

Design Domain is a course that takes place in GSA's School of Design within six programmes: Silversmithing \& Jewellery, Interior Design, Fashion, Textiles, Interaction Design, and Communication Design. It accounts for 20 of the annual 120 credits for first, second and third year students, thus corresponding to SCQF Levels 7, 8 and 9 respectively (Scottish Credit and Qualifications Framework Partnership 2009). Design Domain's defining aim is to create a space for student learners to be more resilient in their own disciplines by considering and being aware of the broader domain of design. As a creative space, Design Domain's places value on learning factors and influences that might be particular to a discipline, and also on those that might be more universally shared - or even derived from another discipline altogether.

As academic coordinator for Design Domain, I am accustomed to the question 'What is Design Domain?' and I will freely confess that explaining Design Domain's distinct identity and purpose is a challenging task. Moreover, at the time of writing, Design Domain constitutes GSA's largest cohort, with a cumulative total of around 450 student learners, including new entrants and continuing, direct entry and study abroad students; and its delivery involves studio teams, technical workshop personnel, visiting tutors and visiting lecturers, all of whom need an understanding of what Design Domain is, and what it is intended to offer. Here the departure point is the course specifications, which also state the Intended Learning Outcomes. At SCQF Level 9, which equates to Year 3, for example, the Course Aim and Indicative Content are articulated asfollows:

To consolidate awareness of design outwith specialist disciplinary areas, and highlight the relationship between specialist subject areas, other design disciplines, and other bodies of knowledge.

A studio-based research-and-practice-led project exploring specific theme(s) surrounding the broad design domain, relative to design subject specialism, supported by seminars, presentations, workshops 
etc. - underpinned by self-directed study producing professional standard outcomes.

Here there is some sense of Design Domain's intentionality. We could argue that it is intended to form a bridging space between the particularity of a singular design specialism and more multifarious areas of knowledge and expertise; and here the words 'relationship' and 'relative' imply a dialogical structure in which no specific part is more important than another. In theoretical terms, the course's framework affords multiplicity in the way of Deleuze \& Guattari's rhizome (1980), particularly in terms of the plurality of bodies of knowledge. Furthermore, the course scaffolding reflects elements of a social constructivist framework as 'an approach to teaching and learning based on the premise that cognition (learning) is the result of mental construction. In other words, students learn by fitting new information together with what they already know' (Mahoney 1991, 97).

However, students and staff may - and do - look at this type of permeable language, and question what, precisely, it means in terms of 'relevant learning activities' (Biggs 2003). After all, as Gosling \& Moon $(2002,11)$ state: 'students have a right to know what they should be learning and the basis on which their work will be judged'. This being so, I developed what I would define as more digestible translations of the specifications for dissemination on cover sheets for Design Domain project briefs and on Design Domain Central, the overall course repository and communication tool on Canvas, GSA's virtual learning environment. Here is one example:

During Design Domain, you explore your own design process by relating it to ideas and practice within your own design subject discipline and to ideas and practice beyond your own discipline in the wider 'domain' of design, including the cross-disciplinary cultural ideas and critical thinking that inform it. Above all, Design Domain asks you to think about what you do, how you do it, and why. It means connecting your work to its broader historical context, to what's happening in the design world now, and to what might happen in the future. In fact, these ideas might not fit neatly into a 'discipline' - they link to bigger concepts, to real world thinking, and to the methods and ideas that inform professional design practice, which often pushes beyond discipline boundaries. It's about developing the confidence to push yourself, too.

While I have iterated and customised this explanation over time, I would argue that it solidifies the nature of Design Domain's learning as essentially decentred. In terms of the overall emphasis on process and critical thinking, and again reflecting practice into theory, one could offer a consonance with social constructionism, particularly in terms of the 'negotiated understandings' emphasised by Burr $(2003,5)$. Furthermore, we could perceive the emphasis on social and cultural context as redolent of connectivism, and the 'nodes' and 'learning community' (Kop \& Hill 2008) that define this pedagogical paradigm do emerge in other defining elements of Design Domain, as we will see a little later on. In 
fact, I view the process inherent to Design Domain as embodying tacit as opposed to codified knowledge, defined by Nonaka \& Toyama $(2003,2)$ in terms of knowledge- creating theory as 'a dialectal process, in which various contradictions are synthesized through dynamic interactions among individuals, the organization and the environment'.

However, as an academic coordinator, I will freely confess these observations are the product of retrospective reflection on lived experience; in other words, Design Domain's rationale is a crystallisation, not a theoretical grounding, and it homes on two key learning characteristics.

The first of these is the notion of 'real world thinking' - a concept that I will admit needles me, since the implication is that this hallowed space is only found sporadically within art \& design higher education. Instead, I would argue that the learning journey encapsulates many of the factors that the graduate designer will face, most notably negotiation, flexibility, the ability to draw creative connections and adaptiveness. However, as Neary \& Beetham $(2015,97)$ point out, 'we experience designed real-world environments as ready for occupation and use, when in fact they are carefully aligned with some uses and relationships and not with others'. As such, Design Domain's learning experience can only be a reflection of the 'real world' in terms of its inherent cross-fertilisation.

The second characteristic is that of crossdisciplinarity, defined by Bremner \& Rodgers $(2013$, 4) as 'an understanding ... of disciplinary difference' in which 'individuals demonstrate disciplinary competence and know how concepts from other disciplines relate to their own, having mastered some of those concepts'; and indeed, it is this aspect of dialogic nutrition that featured significantly in staff discussion on the value of Design Domain. However, it is notable that the term itself is absent from the course specifications, and later in the discussion, we will look at whether this semantic gap should be addressed, and if so, how.

\section{Design Domain: created space}

So far, we have examined the key constructs of Design Domain's experience in terms of what it is intended to enact. We have identified that its context is that of a perceived need for a learning trajectory beyond the specifics of a particular design discipline, and so at this point, we can ask, why was Design Domain conceived within the wider curricular framework? Why was such a shared learning space perceived as useful, and indeed necessary?

Here we meet three key factors that speak to both the particularities and integrative nature of the Design School's curriculum, and it is useful to qualify how Design Domain addresses or mirrors them.

Firstly, when they apply to GSA, student learners specify which programme they intend to follow. As such, they are understandably keen to inhabit their chosen discipline's ways of working from the outset. However, one could argue that here, too, we encounter the paradox of 'real world thinking', for outside the institutional walls, these neat silos are only partially reflected in design process and practice. Once more we can cite Bremner \& Rodgers $(2013,6)$ : 'the boundaries of what were once recognized as discrete design 
disciplines, such as product, graphic, textile, and fashion design, have been ruptured and continue to dissolve'. In seeking to make value of this blurring, Design Domain offers a valuable gloss on what it is to be a designer. However, while some learners view this as a positive - and indeed ask for points of direct collaborative working across studios, an aspect that Design Domain does not currently afford - others regard it as a disruption to the nature of their disciplinary training. Moreover, this is also a challenge that some studio staff have raised, given that they, too, work predominantly within a specific subject specialism.

Secondly, the physicality of campus space could be said to maintain disciplinary separation, with students enacting their studio learning in differentiated areas. If, as Kristensen $(2004,92)$ comments, 'a creative space should allow the peculiarities of the present disciplines to deal with the particulars, while enabling communal space for intensive exchanges and collaboration', such possibilities are structurally limited in building types where studios may be shared within disciplines, but not beyond. In offering a structured creative exchange, Design Domain supports a conceptually expanded field that breaks down these walls, although as we will see, this is enacted at necessarily defined points.

Thirdly, this balance of shared and separate learning spaces is reflected in another 20- credit block, Design History \& Theory, where some provision is elective and across disciplines, and some in the form of pathwayspecific courses. As a part-time lecturer in critical and contextual studies, I reflect Rintoul $(2016,160)$ in arguing for an ideal 'intuitive integration', where teachers and learners embed critical and contextual elements within a 'process' that 'will materialise in practice at unpredictable points'. In fact, I would suggest disciplinary confines are valuable in terms of specialised learning, but can be counterproductive in terms of supporting critical thinking and intrinsic motivation. Design Domain is thus based on the premise that offering a structured collective immersion can act as a support, rather than an impediment, to disciplinary learning experiences.

These three characteristics lay at the heart of the early motivations for the 'created space' of Design Domain, and it is vital to point out that the course was, and is, an object of development. The iteration I discuss here constitutes a substantive change to a pre- existing model, where each studio programme could devolve Design Domain entirely independently, with students choosing to follow either a research and theory pathway, or one based in design process. This led to a structure of regular and spread out teaching blocks over the academic year. However, while the autonomy of delivery was appreciated by many staff, there was the perception of a missing opportunity: to offer a learning experience that at least in some part went beyond the boundaries of disciplinary pathways, and that adhered to a more resolutely collective framework. In initial discussions just before the start of the 2015-16 session - the point at which I came on board as academic coordinator - a new approach was mandated: to bring the 'broad design domain' into stronger relief by unifying the time and pattern of delivery into to two intensive and immersive blocks: the first in Semester 1, the second in Semester 2.Yet while the 'why' of the enterprise was clear, what was less so was the 'how' - and indeed the 'what' of the content and approach. 


\section{Design Domain: creative space}

Intentionality is all very well, but it also requires us to identify ways of thinking and doing that can help us deliver our aims and objectives. This was a lesson that was embodied in core staff discussions on the first iteration of a 'new' Design Domain. One early core challenge was that this revised approach was perceived as a top-down directive, with perhaps less faith in the strategic thought that had gone into it. As such, some staff stakeholders feared that by dint of all programmes doing the same thing, at the same time, disciplinary nuances would be risk. Change is a hard aspect to mandate, but it can be a positive. Indeed, as Bateson (1972, 233), states: 'among groups of people, whether the direction of change is toward homogeneity or complementarity, the achievement is a sharing of premises regarding the meaning and appropriateness of messages and other acts in the context of the relationship'. As academic coordinator, I promoted the beneficial aspects of such a 'relationship' by way of a simple statement: 'parity, not homogeneity'. Moreover, while challenging, such meetings set a vital pattern for Design Domain's development as a creative space: most particularly, involving multiple voices as a means to reassure studio teams that while the course was now centralised, they still possessed the agency to use the course as an adaptive space for their own department's learning aims and objectives. I ensured that staff understood that they could produce their own project briefs for their studios and year groups, meaning then as now that in any given cycle, we might have up to twenty or so different studio activities under Design Domain's umbrella. In fact, some studios work vertically in issuing the same brief to more than one year group, but aligned to the SCQF levels in terms of Intended Learning Outcomes; and others produce quite different projects within the samestudio.

As well as the timings of the course delivery, another innovation in 2015-16 was a mandated unifying element: for all studios, Design Domain would have 'a specific theme(s)', as per the course specifications above. The first of these was A Midsummer Night's Dream: this linked to a large-scale project that had been agreed between GSA, the Royal Conservatoire of Scotland, the University of Glasgow and the BBC Scottish Symphony Orchestra to create a collaborative event to mark William Shakespeare's death anniversary. While the value of such an extracurricular enterprise is undoubtable - and in fact it would be worthy of an article in its own right - its scale and ambition presented considerable challenges to a newly fledged Design Domain. How to align both the subject matter and the extracurricular project's limited demographic of around 30 students to a course that involved hundreds of learners, and some rather anxious staff? Here the question was how to afford both student learners and staff the opportunity to 'contextualise their interpretation of the framework to their particular circumstances, roles, and institutional contexts and strategic objectives' (UK Professional Standards Framework, cited in Lea \& Purcell 2015, 9).

My first step as we prepared for the launch of Design Domain - and indeed for the extracurricular project was to offer explicit reassurance that this was not an exercise in Shakespearean text analysis. To be congruous to this, I did not actively promote the reading, or rereading, of $A$ Midsummer Night's Dream, but instead I focused on articulating subthemes for Design Domain that spoke to some of the territories within it. From this I developed conceptual umbrellas rather than didactic ones: Order/Disorder; Liminal Spaces; Performativity; and Narratives. To explain these subthemes further, and 
as shown in Figure 1, I produced a rationale with further pointer words and terms. This formed the basis both of induction sessions for students and the cover sheet that studio teams used in preparing their project briefs. The whole was bound together under the tagline New Dreams - for what were these if not provocations to a distinct contemporaneity?

\section{ORDER/DISORDER}

Challenging hierarchies (political and familial), power struggles, threat, obedience/disobedience, disruption to the 'natural' or artificial order of things.

\section{LIMINAL SPACES}

Ecologies and environment

(urban/wild, the

forest), enchantment in disruption (e.g. ruin and the ruined space as a place of enchantment), the dream, the nightmare, mythologies illusion and hallucination, sanity/lunacy, animal/human.

\section{NARRATIVES}

Heroes, villains, gender roles, fools, playing out human emotions (love, jealousy, anger/hatred, confusion, deception, fear, manipulation), storytelling (text and image, performance), spoken word, rhythm, voice, plots/stories as microcosms that address wider concerns.

\section{PERFORMATIVITY}

Gender (e.g. crossdressing in terms of renaissance performance), gesture, farce, movement, dance, costume/dress, performative space (e.g. set design, props, projection, sound), sensorial experience (smells, sounds, etc. of the performative experience, past and present).

\section{Fig. 1 Design Domain 2015-16: New Dreams}

At this juncture, it is opportune to point out that while 2015-16's thematic was an exercise in translation of something already in existence, subsequent Design Domain themes have been the product of tabula rasa cocreation. Here the core emphasis is on a series of staff discussions, and when possible, I have conducted brain-storming with student representatives and also with members of staff at GSA's autonomous Student Association, some of whom are former students themselves. In Figure 2, we see how these themes have evolved; and as we proceed to discuss the other binding points of cross-programme cohesion within Design Domain, I would draw particular attention to the theme of 2017- 18 - Bodies, Identities, Action, Engagement - not least because of all of the territories we have explored within Design Domain, these adhere most closely to the inclusivity, ethics and participation frameworks that bind together this issue of iJADE. 
This year's themes of BODIES, IDENTITIES, ACTION, and ENGAGEMENT are incredibly timely. We're living in a world of upheaval and change, and as designers, our practice is also impacted by what we believe, and why we believe it. This is not necessarily about being "political" - instead it's about finding a place in our practice to explore some of the issues that are core to us, and about being able to put forward what these mean to us. These might include how we use our bodies, garments and adornment to display ideas and identities; how we navigate power and class hierarchies; how we hook into debates on civil rights, social justice and race; what gender and race identities mean to us within our contemporary lives; how we use virtual and digital technologies to explore what it means to be 'human' within the face-off between embodied and disembodied; and how issues of migrations and community engagement can be used to enrich our lives and those of others. How do we 'design' ourselves into and within this world scape? How do we engage with practice as critical thinkers and designers?

\begin{tabular}{|l|l|}
\hline BODIES & IDENTITIES \\
$\begin{array}{l}\text { Politics of the body } \\
\text { Politics \& design } \\
\text { Embodied \& disembodied }\end{array}$ & $\begin{array}{l}\text { Gender \& identities } \\
\text { Race \& identities } \\
\text { Class \& power hierarchies }\end{array}$ \\
\hline ACTION & ENGAGEMENT \\
$\begin{array}{l}\text { Activism } \\
\text { Protest \& resistance } \\
\text { Migrations \& communities }\end{array}$ & $\begin{array}{l}\text { Utopias \& dystopias } \\
\text { Communities \& engagement Encounter \& } \\
\text { spectacle }\end{array}$ \\
\hline
\end{tabular}

Fig. 2 Design Domain 2017-18: Bodies, Identities, Action, Engagement

What I had perhaps learnt since 2015-16 was the power of more economical and punchy descriptors for the subthemes, and balancing this with an expanded explanatory paragraph. This was in part responsive to student and staff input, and here I report anecdotally on the basis of a combined approach of student questionnaires and oral feedback (Brennan \& Williams 2004, 23). Some had commented that while the subthemes of 2015-16 had made the Shakespearean subject matter more approachable, their conceptual nature made the aims and intent rather opaque. In view of this, two years in, I had arrived at what I hope to be a happy medium: sufficient clarity, yet enough permeability, to ensure 'the parity but not homogeneity' that was my academic coordinator's by-line better enshrined and protected Design Domain's essential and intrinsic agency.

Along with the binding thematic, another collective aspect that was decided for the new iteration of Design Domain has remained a constant ever since. This is a large-scale launching Symposium, with its programme organised according to the subthemes of that particular academic year, and speakers nominated and invited according to their connections to that particular year's thematics. One of my aspirations is to compile a database of all of the critical thinkers, artists, designers, curators and wider practitioners we have brought in - and I recall how one speaker commented to me afterwards: 'lucky, lucky, students'. Given the work involved in its construction, luck may have little to do with it, but the great fortune of the Symposium is also what some students perceive to be its drawback: that the talks are not intended to have direct links to the specifics of their studio project briefs, but instead are designed to act as a provocative and inspirational launch-pad for their critical thinking. 
The third and final of these collective points of meeting is Open Studios, which take place at the end of each of Design Domain's semester blocks, just in advance the course's formative and summative assessment points. In Open Studios, in a short, intensive building take over, student learners install work within the studio spaces and common areas of the School of Design, and here the scale and variety of outputs becomes visibly apparent. This can constitute a vast range of outputs: from singular or multiple artefacts, to film and soundwork, samples, and research and reflective documentation. Some studio teams require their students to textually articulate how they arrived at their endpoint from the inspiration or provocation of the Design Domain thematics; in others, the handling is deliberately looser; and to better explain what each studio grouping has been up to, I produce a leaflet that briefly summarises each project brief. What unifies Open Studios is a sense of opportunity: as students have commented to me, they rarely have an explicit occasion to view the entirety of the School of Design's studios, and by default each other's work, on such a vast and unimpeded scale. Together, the Symposium and Open Studios afford a 'right to roam' element within Design Domain that makes value of the various disciplines and indeed disciplinarities at stake. However, I will confess that while the term 'crossdisciplinary' is often bandied, within these particular learning experiences it feels more appropriate to focus on ways of thinking than prescribing ways of doing, and we shall now explore the power and paradoxes of defining disciplinarities.

\section{'Design Domainarity'}

As we have seen, Design Domain is a course that has been subject to close interrogation, and indeed substantial revision, as a learning experience. But how to define it? As a provocation in and of itself, I would offer that it is less challenging to state what it is not. For example, while it is not mentioned in Design Domain's course specifications, collaboration between studios was, and remains, a desirable possibility - but given the sheer number of groupings that would be involved, the complexity of how to assess, and indeed how to map these relationships, has so far been a deciding factor to leave this aside. However, moving forwards, from this coming academic year, Design Domain will be run over Year 2 and Year 3 only, given that our SCQF Level 7 students will be engaged in a new course structure, the First Year Experience. It will be interesting to see how Design Domain might gently flex its identity and parameters within its new and slightly smaller cohort, and one already known change is that we shall have two Symposia, one for each semester block, rather than one.

At the very least, Design Domain's course specifications might require a slightly nuanced revisiting, not least since almost four years into the revised iteration, we could try to more explicitly match them to the lived experience of Design Domain, in a way that is perhaps more accurately reflected in the 'translations' of its intentionality on project briefs and Canvas documentation. As we saw above, for instance, the course specifications make no mention of one core characteristic that arose in discussions about Design Domain's revision, namely crossdisciplinarity. I would suggest that it is timely and indeed essential to ask if this is the correct defining term; and it is precisely this territory that I am in the process of questioning in the initial stages of an action research-informed project for a Postgraduate Certificate in Learning and Teaching (PGCert).

Indeed, any course of study that appears to go beyond discipline specialisms may require us to embody, inhabit and activate such definitions more deeply, and indeed to translate their intention to student learners and to the staff who deliver course content. Perhaps the most deceptively simple of the various disciplinarities is intradisciplinarity, or working within a single discipline. We could argue this to be a key characteristic of a design institution where students apply to a specific studio programme, as is the case at ARTCOL; and for the most part, Design Domain project briefs adhere to a model of delivery within the discipline, even if student learners are exposed to voices and ways of thinking from without. Crossdisciplinarity - the most frequently applied to Design 
Domain, as I underlined above - entails viewing one discipline from the perspective of another. Here, I would argue that the deliberate boundary disruption of the Symposium and Open Studios does, to a large extent, reflect this sort of approach, but that the project briefs in and of themselves do not always. However, the intent to go beyond disciplinary boundaries might also lead to multidisciplinarity, or pluridisciplinarity; and here I draw on Blevis \& Stolterman $(2009,48)$, who frame this as an endeavour to utilise 'coordinated outputs from distinct collections of methods informed by or in the service of respective distinct bodies of knowledge'. To this we can add interdisciplinarity, 'an approach to a particular problem space using integrated outputs from combined collections of methods informed by or in the service of combined bodies of knowledge'. Transdisciplinarity is arguably the most alchemical of all: it drives towards 'a broader goal: transcending disciplinarity and using collections of methods and their associated bodies of knowledge on an as needed basis as required' (Blevis \& Stolterman 2009, 49).

Blevis \& Stolterman unpack these definitions within an interaction design framework, and in particular, they relate the last three to unpacking the value and challenges within team work. This exemplifies how these last three 'paradisciplinarities', as I would like to term them, tend to find their most consistent articulation within broader debates on 'the taxonomies of types of disciplinary collaboration' (Rogers et al. 2005, 283). However, I would argue that these nuances of translation and application can be usefully reappraised when we examine a pedagogical framework like Design Domain, which blends predominantly individual learning with particular and specific points of collective commonality of purpose and action. Indeed, I would be interested to explore Design Domain in relation to course models in other art \& design institutions in the UK and beyond to ask, what nutritional value do such frameworks encapsulate, and how do and should educators and student learners understand them? Is it important - or even crucial to use such taxonomies when explaining and communicating our aims and objectives? While such a discussion is subject to further development, at this juncture I instinctively adhere to the stance espoused by Bremner \& Rodgers $(2013,9)$, who argue that particularly in a digital age, 'we might now need to consider 'alter-disciplinarity' or 'undisciplinarity' as the most effective approach for the future of design'. As such, I would suggest that a meaningful lens for my developing investigation is 'Design Domainarity', and it is my intention to further my understanding of what this entails in my PGCert evaluation study.

\section{Design Domain: the value of not knowing?}

To briefly describe how I will probe 'Design Domainarity', my departure point is perhaps the most defining competency of my role as academic coordinator: to talk to people, and unpack what they think, and why they think it. From the standpoint that students and teachers are 'partners in learning' (Healey et al. 2015, 151), I will conduct this reflective evaluation on the basis of a small focus group of staff and student interviewees, with my case study a project in Communication Design from the 2017-18 iteration of Design Domain. Within it - and somewhat unusually - students from the three third year specialisms, namely graphic design, photography and illustration - worked collaboratively on a live brief to design a logo and window displays for ShelterScotland.

While more than a year has passed since this Communication Design project took place, the value of this distance is that the staff involved have reflected their own learning back into the 2018-19 cycle. Furthermore, student learners have since completed their degree level work, with this year's graduating cohort being the first to complete the cycle of the 'new' Design Domain. As Harvey \& Stensaker $(2008,435)$, propose, 'instead of starting by asking "who do we want to be?" perhaps a better question would be "who are we?"' On the premise that a critical understanding of value is often enacted in hindsight, looking back in order to look forwards feels highly congruous. In turn, this might help us better problematise and thus define Design Domain's identity as a curriculum element, on the basis of 'categories of description [that] emerge 
from the analysis of the participants' descriptions of their experiences' (Fraser \& Bosanquet 2006, 270). Certainly, I wouldoffer that framing and creating a curricular space is a heuristic process, perhaps even one of trial and error.

For the most part, the types of critical questions I have framed for staff and student respondents centre on the experience of Design Domain in terms of their perception of its learning motivations and its positives and challenges. I also present them with a taxonomy of disciplinarity, asking which definitions ring most true in terms of their value. Paraphrasing Orr (2011), I will frame my enquiry within an opening conception of 'Design Domainarity': that it is a rhizomatic ecology of connections of identities and values. But within more familiar taxonomy of disciplinarities, how should we define the intentionality of Design Domain's learning experience? And is this a useful and vital endeavour? Or, like Fisher \& Fortnum (2013), can we argue that there is value in not knowing?

\section{Conclusion}

Art \& design higher education presents rich opportunities for operating in an expanded field of thinking. However, as supporters for learning, we need to understand our own intentionality as educators, as well as communicating our aims to students as clearly as possible 'to make sure that they do not falter for reasons within our control' (Ramsden 2002, 142). But when such processes are driven by and driving change (Bateson 1972), this is particularly pertinent, and Design Domain's context, intentionality and enactment have been developed to afford student learners, and indeed studio staff, the agency to make meaningful connections of ideas and experiences. Above all, Design Domain functions on the premise that training within a discipline is made more resilient, and indeed transferable, by operating it in an expanded field. In these terms, we could argue that the taxonomy of disciplinarities might be usefully reappraised when applied to a pedagogical framework like Design Domain, which derives oxygen and nutrition from a multiplicity of ways of thinking, making and doing, and which blends predominantly individual learning with particular and specific points of collective commonality of purpose and action. It is this territory that I will further test and evaluate via an action research informed appraisal of a recent Design Domain project in Communication Design, and I have outlined the types of critical questions to be asked of staff and student respondents. While my conclusions remain to be fully tested, I offer a preliminary suspicion: that to bring practice and process into a more adaptive theoretical framework, it is perhaps more appropriate to focus on ways of thinking than prescribing ways of doing. In these terms, I would suggest that there is significant value in 'Design Domainarity' as a created and creative space, and I look forward to following its journey 


\section{Funding Information}

\section{The Glasgow School of Art}

\section{References}

Bateson, G. (1972) Steps to an Ecology of Mind. New York: Ballantyne Books.

Biggs, J. (2003) Aligning Teaching for Constructing Learning, Higher Education Academy (online). Available at: www.heacademy.ac.uk/system/files/resources/id477_aligning_teaching_for_constructi (accessed 26 June 2017).

Blevis, E. \& Stolterman, E. (2009) Transcending disciplinary boundaries in interaction design, Interactions, Vol. 16, No. 5, pp. 48-51.

Bremner, C. \& Rodgers, P.(2013) Design without discipline, Design Issues, Vol. 29, No. 3, pp. 4-13.

Brennan, J. \& Williams, R. (2004) Collecting and Using Student Feedback: A Guide to Good Practice. Learning and Teaching Support Network (online). Available at:

www.heacademy.ac.uk/system/files/id352_collectin (accessed 23 March 2017).

Burr, V. (2003) Social Constructionism. London: Routledge.

Deleuze, G. \& Guattari, F.(1980; trans. B. Massumi 1987) A Thousand Plateaus: Capitalism and Schizophrenia. Minneapolis: University of Minnesota Press.

Fisher, E. \& Fortnum, R. (2013) On Not Knowing: How Artists Think. London: Black Dog Publishing.

Fraser, S. P.\& Bosanquet, A. (2006) The curriculum? That's just a unit outline, isn't it? Studies in Higher Education, Vol. 31, No. 3, pp. 269-84.

Gosling, D. \& Moon, J. (2002) How to Use Learning Outcomes and Assessment Criteria. London: SEEC.

Harvey, L. \& Stensaker, B. (2008) Quality culture: understandings, boundaries and linkages, European Journal of Education, Vol. 43, No. 4, pp. 427-42.

Healey, M., Bovill, C. \& Jenkins, A. (2015) Students as partners in learning, in J. Lea [Ed.] Enhancing Learning and Teaching in Higher Education: Engaging with the Dimensions of Practice. Milton Keynes: Open University Press, pp. 141-72.

Kop, R. \& Hill, A. (2008) Connectivism: Learning Theory of the Future or Vestige of the Past? International Review of Research in Open and Distributed Learning, Vol. 9, No. 3 (online). Available at:

http://www.irrodl.org/index.php/irrodl/article/view/9.3.4 (accessed19 June 2019). 
Kristensen, T.(2004) The physical context of creativity, Creativityand Innovation Management, Vol. 13, No. 2, pp.89-96.

Lea, J. \& Purcell, N. (2015) Introduction: the scholarship of teaching and learning, the Higher Education Academy, and the UK Professional Standards Framework, in J. Lea [Ed.] Enhancing Teaching and Learning in Higher Education: Engaging with the Dimensions of Practice. Maidenhead: Open University Press, pp. 1-16.

Mahoney, M. J. (1991) Human Change Processes. New York: Basic Books.

Neary, M. \& Beetham, H. (2015) The nature of academic space, in J. Lea [Ed.] Enhancing Learning and Teaching in Higher Education: Engaging with the Dimensions of Practice. Maidenhead: Open University Press, pp. 83-112.

Nonaka, I. \& Toyama, R. (2003) The knowledge-creating theory revisited:

knowledge creation as a synthesizing process, Knowledge Management Research \& Practice, Vol. 1, No. 2, pp.2-10.

Orr, S. (2011) 'Being an artist you kind of, I mean, you get used to excellence':identity, values and fine art assessment practices, International Journal of Art \& Design Education, Vol. 30, No. 1, pp. 37-44.

Ramsden, P. (2002) Learning to Teach in Higher Education. London and New York: RoutledgeFalmer.

Rintoul, J. (2016) Integrating Critical and Contextual Studies in Art and Design. Oxford: Routledge.

Rogers, Y., Scaife, M. \& Rizzo, A. (2005) Interdisciplinarity: an emergent or engineered process? in S. J. Derry, C. D. Schunn \& M. A. Gernsbacher [Eds] Interdisciplinary Collaboration. Mahwah, NJ: Lawrence Erlbaum Associates, pp. 265-86.

Scottish Credit and Qualifications Framework Partnership (2009) SCQF Handbook: User Guide (online). Available at: http://scqf.org.uk/content/files/SCQF\%20handbook\%20FULL\%20-

\%20amended\%20Dec\%2009.pdf (accessed 7 Jan 2017) 

